\title{
Image Quality Degradation from Transmit Delay Profile Quantization
}

\author{
Stuart, Matthias Bo; Jensen, Jonas; di lanni, Tommaso; Jensen, Jørgen Arendt
}

Published in:

Proceedings of 2015 IEEE International Ultrasonics Symposium

Link to article, DOI:

10.1109/ULTSYM.2015.0126

Publication date:

2015

Document Version

Peer reviewed version

Link back to DTU Orbit

Citation $(A P A)$ :

Stuart, M. B., Jensen, J., di lanni, T., \& Jensen, J. A. (2015). Image Quality Degradation from Transmit Delay Profile Quantization. In Proceedings of 2015 IEEE International Ultrasonics Symposium IEEE.

https://doi.org/10.1109/ULTSYM.2015.0126

\section{General rights}

Copyright and moral rights for the publications made accessible in the public portal are retained by the authors and/or other copyright owners and it is a condition of accessing publications that users recognise and abide by the legal requirements associated with these rights.

- Users may download and print one copy of any publication from the public portal for the purpose of private study or research.

- You may not further distribute the material or use it for any profit-making activity or commercial gain

- You may freely distribute the URL identifying the publication in the public portal 


\title{
Image Quality Degradation from Transmit Delay Profile Quantization
}

\author{
Matthias Bo Stuart, Jonas Jensen, Tommaso Di Ianni, and Jørgen Arendt Jensen \\ Center for Fast Ultrasound Imaging, Dept. of Elec. Eng., Bldg. 349, Technical University of Denmark, \\ 2800 Kgs. Lyngby, Denmark
}

\begin{abstract}
The investigated hypothesis is that quantization of the transmit delay profiles degrades the image quality in plane wave ultrasound imaging. Simulated point spread functions show that transmit delay profile quantization gives rise to artefacts behind the point target. The axial and lateral $6 \mathrm{~dB}$ resolution is unaffected, but contrast is reduced. This is quantified by a 20 dB cystic resolution of $1.23 \mathrm{~mm}$ compared to $0.53 \mathrm{~mm}$ for the ideal (non-quantized) case at $10 \mathrm{~mm}$ depth. It is also shown that providing individually phase-shifted excitation waveforms to each element restores the image quality, as seen by the $20 \mathrm{~dB}$ cystic resolution being restored to $0.53 \mathrm{~mm}$. The impact on high-quality imaging is discussed.
\end{abstract}

\section{INTRODUCTION}

Modern ultrasound systems rely on digital backends for high quality imaging. Current hardware allows real-time implementation of advanced beamforming algorithms such as synthetic aperture imaging [1] with advanced interpolation schemes for subsample precision required for high-quality imaging [2]. For many years, delay quantization has thus not been an issue in receive beamforming.

However, the transmit hardware typically does not allow compensating for temporal quantization effects: A shared sampling clock is used to read out a single waveform to all transmit elements at different times corresponding to the desired delays. The effect of such a setup is shown in Fig. 1, where the point spread function (PSF) is shown for an imaging setup using 10 plane waves steered from $-9^{\circ}$ to $+9^{\circ}$. On the left, a reference image with non-quantized delay profiles is shown, while in the middle image the delay profiles have been quantized to a $70 \mathrm{MHz}$ sampling clock. The right side image is described later. The shadow behind the PSF in the middle image leads to reduced contrast in B-mode imaging, and energy leaking from tissue into the vessel in flow imaging.

The effects of delay quantization have been studied in RADAR [3] and ultrasound [4] since the 1960s and 1970s respectively. In RADAR, only the far-field is considered. In ultrasound, quantization lobes with behaviour similar to grating lobes have been investigated analytically [4] and their effects on imaging have been studied through measurements [5], [6]. Peterson and Kino [7] also studied near-field effects and showed that broadband excitations reduce the quantization lobes. Common to these studies is that only lateral or angular effects are shown on PSFs, while the axial effects have not been studied.

The hypothesis being investigated here is that delay profile quantization causes image quality degradation in all spatial dimensions. First the theory behind quantization effects is briefly summarized in Section II. The simulation setup is described in Section III, results are presented in Section IV and discussed in Section V. Conclusions are given in Section VI.

\section{QuAnTIZATION EFFECTS}

This section gives a brief introduction to the basic theory of quantization effects. For more thorough treatments and worstcase analysis see the work by Peterson and Kino [7] and Holm and Kristoffersen [8].

For a given transducer array the delay profile required to emit a plane wave in a direction $\vec{d}$ is calculated as

$$
t_{i}=\frac{\vec{d} \cdot \vec{r}_{i}}{c}
$$

where $r_{i}$ are the coordinates of the $i$ th element, $c$ is the speed of sound, and $t_{i}$ is the delay of the $i$ th element. These delays are then quantized to a transmit sampling frequency $f_{s, t x}$ as follows

$$
\hat{s}_{i}=\operatorname{round}\left(t_{i} f_{s, t x}\right) \text {, }
$$

where $\hat{s}_{i}$ is the sample index at which the $i$ th element should fire. The quantized delay $\hat{t}_{i}$ is found by

$$
\hat{t}_{i}=\frac{\hat{s}_{i}}{f_{s, t x}} .
$$

Defining $m$ as the oversampling relative to the center frequency of the excitation waveform $f_{0}$,

$$
m=\frac{f_{s, t x}}{f_{0}},
$$

it can be deduced [8] that the phase error falls in the range

$$
e \in\left[\frac{-\pi}{m} ; \frac{\pi}{m}\right]
$$

which will be used later.

Considering (2), the concept of error-free steering angles $\theta_{e f, k}$ can be introduced for a linear or phased array. These are the steering angles for which $\hat{s}_{i}-\hat{s}_{i-1}=k$, where $k$ is an integer, i.e., considering the delay profile in a Cartesian coordinate system with the abscissa unit being element index and the ordinate unit delay in clock cycles, then the slope of the straight line representing the delay profile is $k$ quantization intervals. In Fig. 2, $\theta_{e f, k}$ are found through basic trigonometry as

$$
\theta_{e f, k}=\arcsin \frac{k c}{a f_{s, t x}},
$$



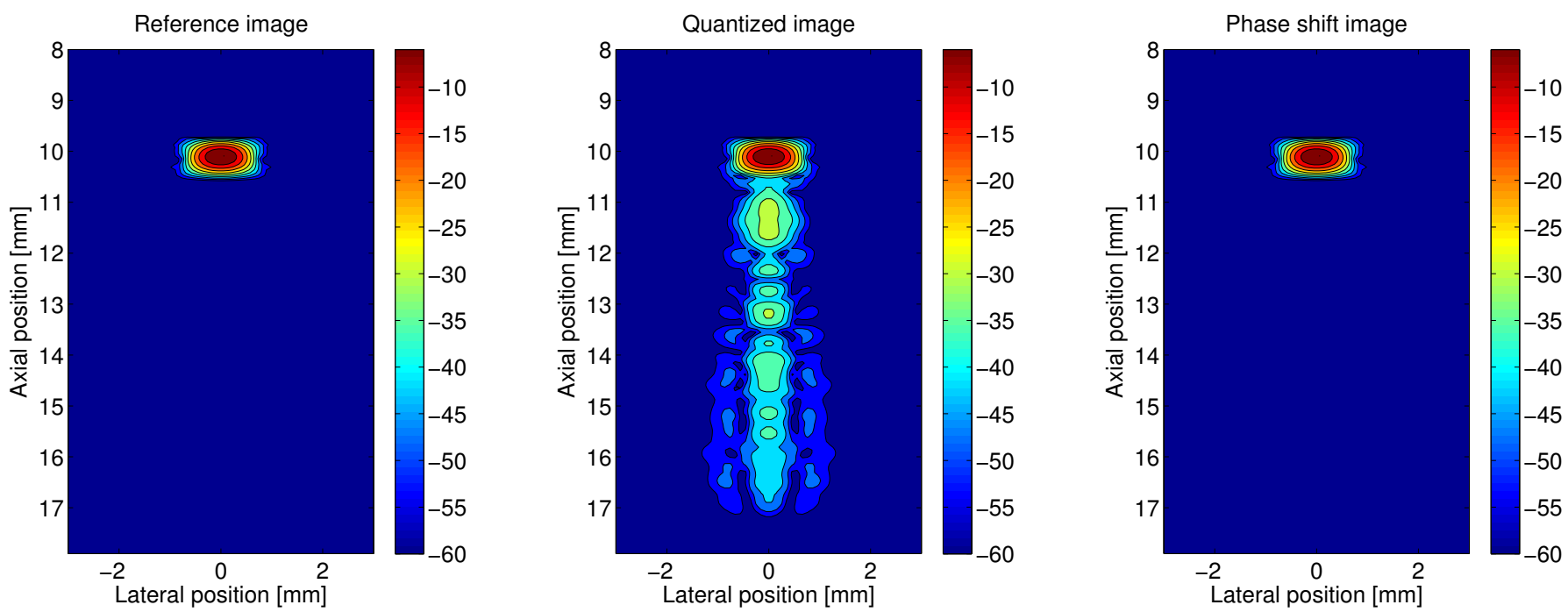

Fig. 1. The PSF for the reference and quantized setups for an acquisition sequence with 10 plane waves steered between $-9^{\circ}$ and $+9^{\circ}$.

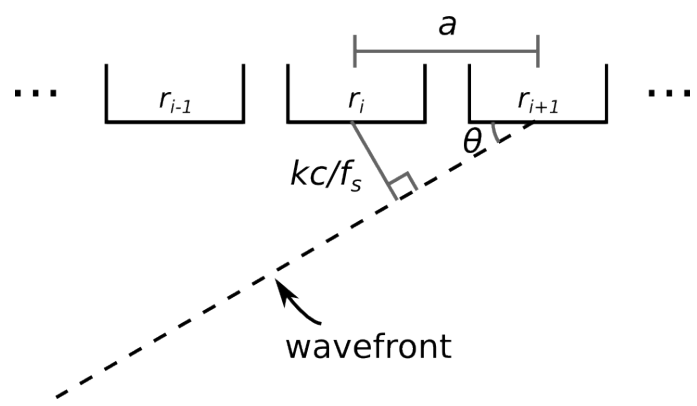

Fig. 2. Illustration of the calculation of error free steering angles.

where $a$ is the interelement distance or pitch. For a $\lambda$-pitch, $7 \mathrm{MHz}$ array with $c=1540 \mathrm{~m} / \mathrm{s}, \theta_{e f, 1} \approx 5.74^{\circ}, \theta_{\text {ef }, 2} \approx 11.54^{\circ}$ etc. All other steering angles will be influenced by quantization errors. Note that lowering the transducer pitch increases $\theta_{e f, k}$ meaning that a $\lambda / 2$-pitch array has a larger $\theta_{e f, k}$ than a $\lambda$ pitch array of the same frequency, i.e., over a given steering range phased arrays have fewer error-free steering angles than linear arrays of the same frequency.

\section{Simulation Setup}

Field II [9], [10] simulations have been carried out to investigate the quantization effects. Both the transmit field and the PSF have been investigated. For all simulations, a 384 element, $7 \mathrm{MHz}$ array with $104 \mu \mathrm{m}$ pitch, speed of sound $1540 \mathrm{~m} / \mathrm{s}$, and $f_{s, t x}=70 \mathrm{MHz}$ has been used. Three simulation setups have been used for both transmit field and PSF.

- Reference: By default, Field II interpolates in the impulse responses, effectively eliminating quantization effects in the temporal domain. This setup is used as a reference.

- Quantization: In this setup, the delay profile provided to Field II has been quantized according to the given sampling frequency of the transmit waveforms, $f_{s, t x}$.
Here $f_{s, t x}=70 \mathrm{MHz}$ is used, as that is the sampling frequency in the SARUS research scanner [11]. This setup corresponds to the default operating mode of ultrasound scanners.

- Phase-shift: In this setup, the quantized delay profiles are still used, but each element is given a unique phaseshifted excitation waveform, where the phase-shift cancels the phase error introduced by the quantization. In this way, the transmit field from the reference should be recovered, assuming a linear transmitter is employed.

\section{RESUlts}

For investigating the transmit field, the pressure wave along a line parallel to the desired wavefront is calculated. Fig. 3 shows this for the reference, the quantized, and the phase-shift corrected setups for a plane wave steered at $9^{\circ}$. The quantization introduces disturbances in the field, which are corrected by the phase-shift setup. The details of these disturbances are discussed below.

Fig. 1 shows the PSF for a scatterer at $10 \mathrm{~mm}$ depth for the reference and quantized setups. The PSFs for the reference and phase-shift setups are shown on the left and right respectively. The artefacts from the quantized delay profiles have disappeared.

The full-width at half maximum (FWHM) is identical both axially $(1.4 \lambda)$ and laterally $(2.8 \lambda)$ for all three setups at $10 \mathrm{~mm}$ depth. However, the $20 \mathrm{~dB}$ cystic resolution (R20dB) [12] the radius an anechoic region must have to appear $20 \mathrm{~dB}$ below the surrounding tissue - goes from $0.53 \mathrm{~mm}$ for the reference to $1.23 \mathrm{~mm}$ for the quantized setup. For the phase-shift setup, the image quality of the reference is restored with an $\mathrm{R} 20 \mathrm{~dB}$ of $0.53 \mathrm{~mm}$.

\section{DISCUSSION}

In the transmit field in Fig. 3, the large side-lobes (quantization lobes) have behaviour similar to that of grating lobes 

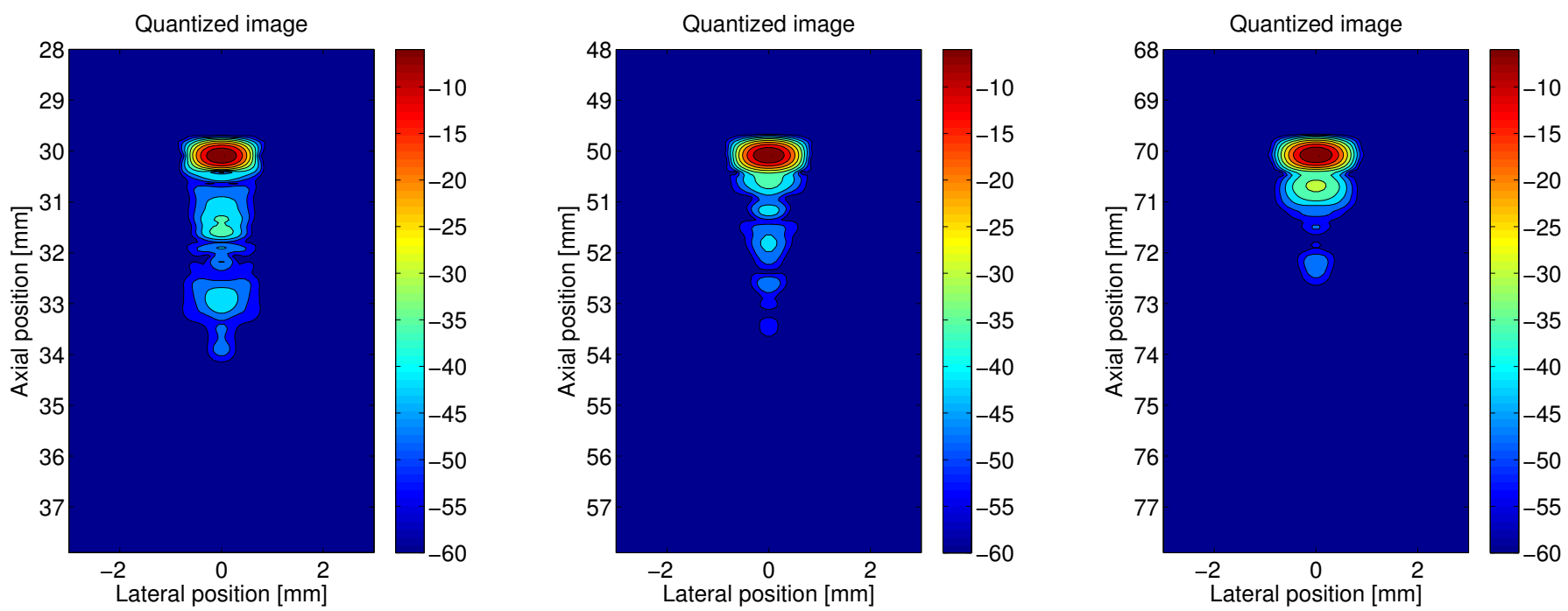

Fig. 5. The PSF at 30, 50, and $70 \mathrm{~mm}$ depths for the quantized setup.

[8], while the distinct lines within the quantization lobes are similar to edge waves from unapodized transmit apertures. They originate from points on the aperture, where the phase error wraps around the interval in (5). The artefacts in the PSF however stem from the region immediately behind the main wavefront at the top of the figures.

Fig. 4 shows the transmit field for the quantized setup at $30 \mathrm{~mm}, 50 \mathrm{~mm}$, and $70 \mathrm{~mm}$ depth for a $9^{\circ}$ steering angle, while Fig. 5 shows the PSFs at the same depths for the setup used above (10 plane waves between $-9^{\circ}$ and $+9^{\circ}$ ). Fig. 5 shows that the artefacts diminish with increasing depth, which corresponds well with the reduced amount of clutter immediately behind the main wavefront seen in Fig. 4.

As previously mentioned, the quantized setup corresponds to the default operating mode of many ultrasound scanners. High-quality imaging requires high precision in the delay calculation and associated interpolation in order to minimize side-lobe levels and maximize contrast [2]. Similarly, other undesired artefacts outside the main response of the PSF should be minimized. In medical ultrasound, the artefacts shown here will lead to clutter behind strong reflectors or inside hypoechoic regions such as cysts and vessels.

The proposed correction - phase-shifting the excitation waveforms to each element - requires both hardware and software support, while it assumes a linear transmitter. A correction for scanners using digital on/off pulsers remains to be found. The effect on focused and defocused beams should also be investigated, as similar effects are expected.

\section{CONCLUSION}

Transmit delay profile quantization has been shown to negatively impact image quality for plane wave imaging. The quantization affects the contrast in a depth dependent manner with larger impact at shallow depths. Using individually phaseshifted excitation waveforms for each element restores the image quality.

\section{ACKNOWLEDGMENT}

This work was supported by grant 82-2012-4 from the Danish Advanced Technology Foundation and by BK Ultrasound Aps.

\section{REFERENCES}

[1] J. M. Hansen, D. Schaa, and J. A. Jensen, "Synthetic aperture beamformation using the gpu," in Proc. IEEE Ultrason. Symp., 2011, pp. 373-376.

[2] H. Andresen, S. I. Nikolov, and J. A. Jensen, "Precise time-of-flight calculation for 3D synthetic aperture focusing," IEEE Trans. Ultrason., Ferroelec., Freq. Contr., vol. 56, no. 9, pp. 1880-1887, 2009.

[3] T. C. Cheston and J. Frank, "Array antennas," The Johns Hopkins University, Applied Physics Laboratory, Tech. Rep., 1968.

[4] W. L. Beaver, "Phase error effects in phased array beam steering," in Proc. IEEE Ultrason. Symp., 1977, pp. 264-267.

[5] P. A. Magnin, O. T. von Ramm, and F. L. Thurstone, "Delay quantization error in phased array images," IEEE Trans. Son. Ultrason., vol. 28, no. 5, pp. 305-310, 1981.

[6] O. T. von Ramm and S. W. Smith, "Beam steering with linear arrays," IEEE Trans. Ultrason., Ferroelec., Freq. Contr., vol. 30, no. 8, pp. 438452, Aug 1983.

[7] D. K. Peterson and G. S. Kino, "Real-time digital image reconstruction: A description of imaging hardware and an analysis of quantization errors," IEEE Trans. Son. Ultrason., vol. 31, no. 4, pp. 337-351, Jul 1984.

[8] S. Holm and K. Kristoffersen, "Analysis of worst-case phase quantization sidelobes in focused beamforming," IEEE Trans. Ultrason., Ferroelec., Freq. Contr., vol. 39, pp. 593-599, 1992.

[9] J. A. Jensen and N. B. Svendsen, "Calculation of pressure fields from arbitrarily shaped, apodized, and excited ultrasound transducers," IEEE Trans. Ultrason., Ferroelec., Freq. Contr., vol. 39, pp. 262-267, 1992.

[10] J. A. Jensen, "Field: A program for simulating ultrasound systems," Med. Biol. Eng. Comp., vol. 10th Nordic-Baltic Conference on Biomedical Imaging, Vol. 4, Supplement 1, Part 1, pp. 351-353, 1996.

[11] J. A. Jensen, H. Holten-Lund, R. T. Nilsson, M. Hansen, U. D. Larsen, R. P. Domsten, B. G. Tomov, M. B. Stuart, S. I. Nikolov, M. J. Pihl, Y. Du, J. H. Rasmussen, and M. F. Rasmussen, "SARUS: A synthetic aperture real-time ultrasound system," IEEE Trans. Ultrason., Ferroelec., Freq. Contr., vol. 60, no. 9, pp. 1838-1852, 2013.

[12] K. Ranganathan and W. F. Walker, "Cystic resolution: A performance metric for ultrasound imaging systems," IEEE Trans. Ultrason., Ferroelec., Freq. Contr., vol. 54, no. 4, pp. 782-792, 2007. 

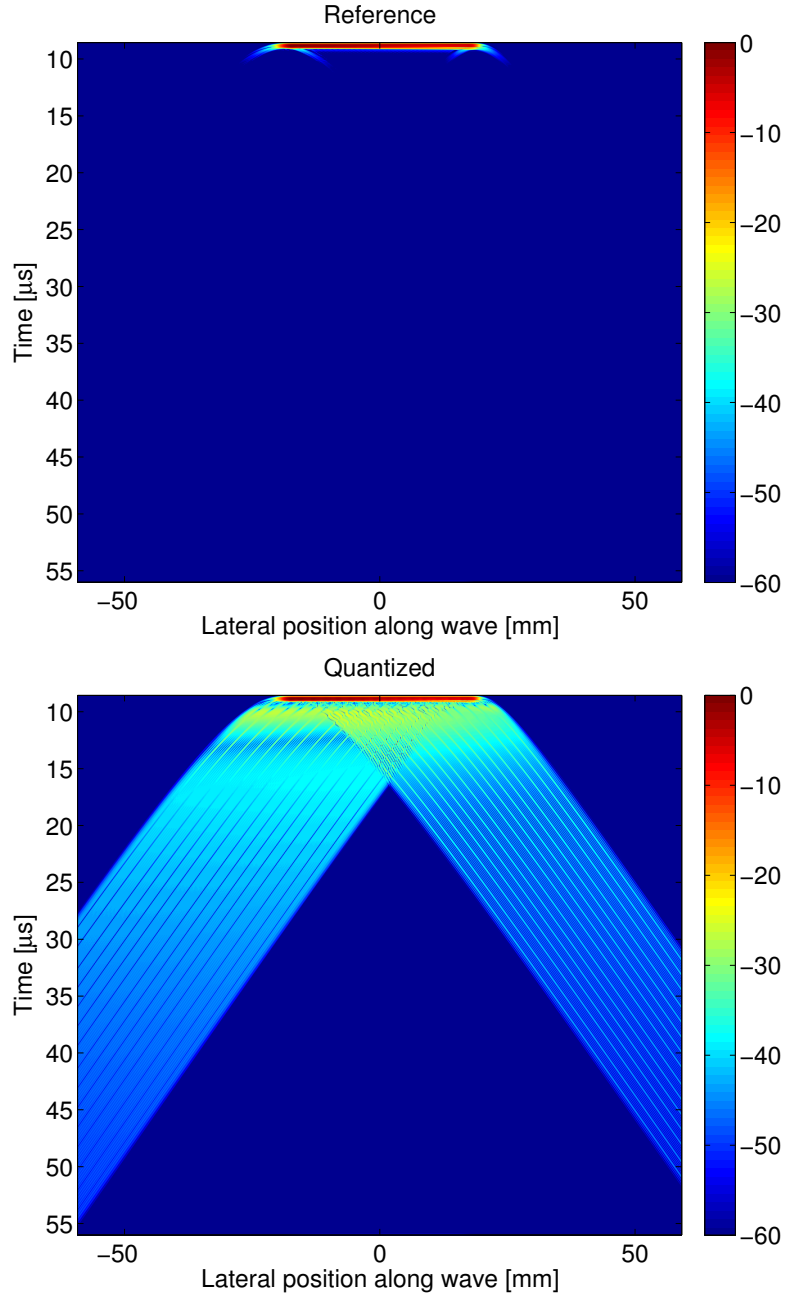

Phase shifted

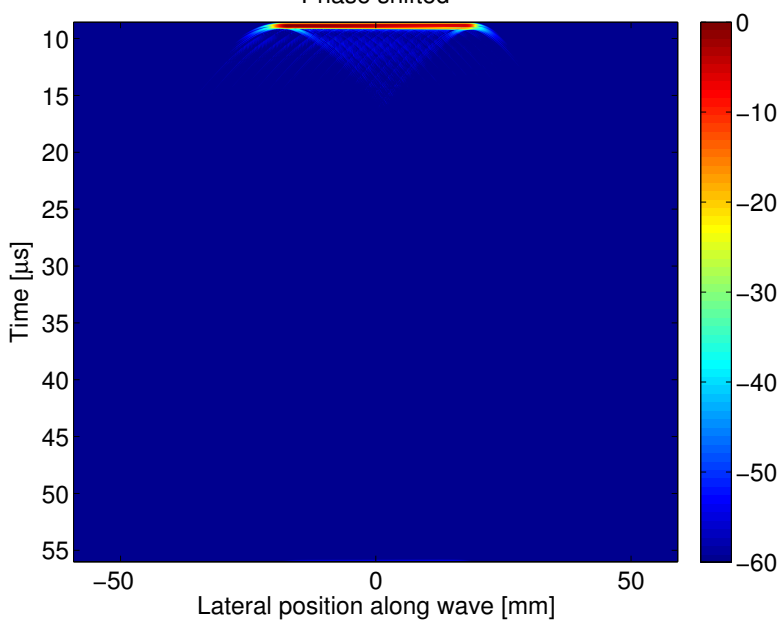

Fig. 3. Simulated transmit fields for a plane wave steered at $9^{\circ}$ at $10 \mathrm{~mm}$ depth. The $x$-axis is parallel to the wavefront, i.e., the coordinate system has been rotated relative to the transducer.

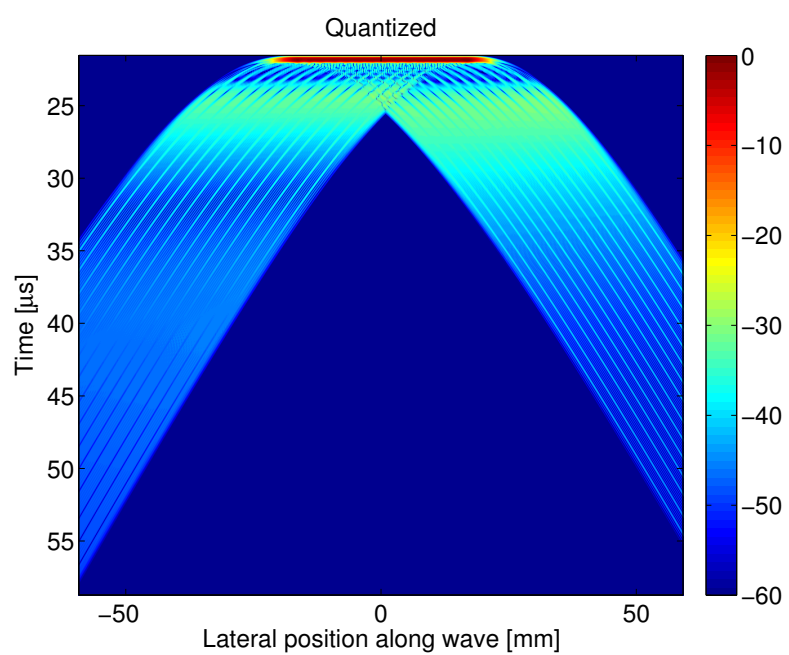

Quantized
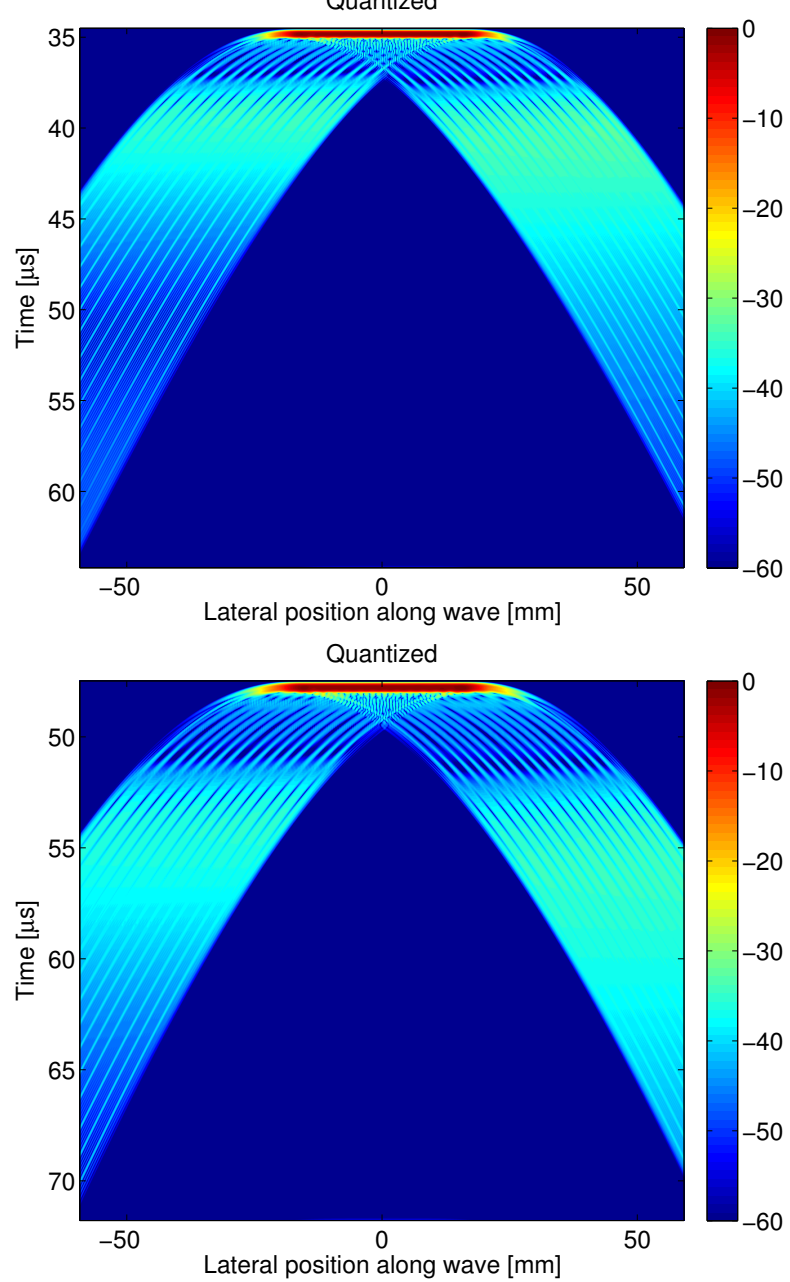

Fig. 4. The transmit field at 30, 50, and $70 \mathrm{~mm}$ depths for a plane wave steered at $9^{\circ}$ with the quantized setup. 